\title{
The Mismeasure of Desire: The Science, Theory and Ethics of Sexual Orientation
}

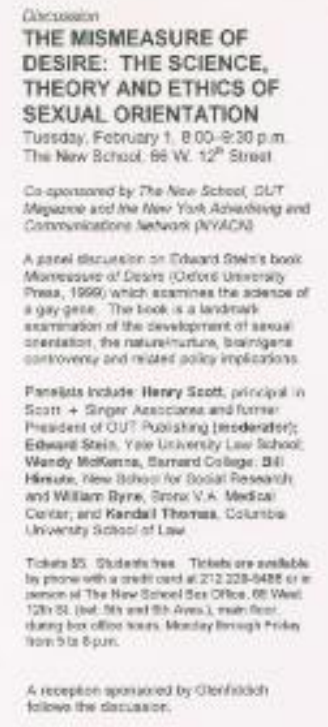

\section{Related Collection}

New School Office of Communications, George Calderaro records $\rightarrow$ Binders (NS030103.01)

\section{Description}

This item constitutes part of Public Relations Books 1-3. While the majority of records compiled into the books are press releases, other formats may be present.

\section{Date}

1999

\section{Related person}

New School University (author)

\section{Work Type}

press releases

Page 1 of 2 


\section{Use Restrictions}

http://rightsstatements.org/vocab/lnC/1.0/

\section{Location}

box 2 , folder 1

Identifier

NS030103_000341

Page 2 of 2 